\title{
ANALISIS PELAPORAN PAJAK PERTAMBAHAN NILAI (PPN) PADA PT. BUMI MITRA BUTON ABADI
}

\author{
Waode Adriani Hasan \\ Program Studi Akuntansi, Fakultas Ekonomi \\ Universitas Muhammadiyah Buton, Baubau, Indonesia \\ e-mail :adriani.hasan@umbuton.ac.id
}

\begin{abstract}
ABSTRAK
Penelitian ini bertujuan untuk mendeskripsikan dan menganalisis prosedur pelaporan pajak pertambahan nilai PT. Bumi Mitra Buton Abadi sesuai dengan undang-undang perpajakan yakni Undang-Undang Nomor 42 Tahun 2009.

Metode penelitian yang digunakan adalah metode analisis deskriptif kualitatif.Hasil penelitian menunjukan bahwa prosedur pelaporan pajak pertambahan nilai pada PT. Bumi Mitra Buton Abadi pada tahun 2014 dan 2015 belum menaati prosedur pelaporan yakni terlapor kosong ( 0 ) dan tanggal pelaporan dilakukan di tahun 2016. Namun pada tahun 2016 PT. Bumi Mitra Buton Abadi melakukan prosedur pelaporan dengan benar. Akibat kesalahan di tahun 2014 dan 2015 PT. Bumi Mitra Buton Abadi mendapat sanksi pajak berupa pemeriksaan. Sanksi yang didapat oleh PT. Bumi Mitra Buton Abadi dapat terampuni dengan memanfaatkan program tax amnesty atau pengampunan pajak pada tahap pertama yang diadakan oleh pemerintah.
\end{abstract}

\section{Kata Kunci: Pajak, Pelaporan Pajak, Pajak Pertambahan Nilai}

\section{ABSTRACT}

This study aims to describe and analyze procedures for reporting value added tax of PT. Bumi Mitra Buton Abadi is in accordance with the taxation law, Law Number 42 of 2009.

The research method used is a qualitative descriptive analysis method. The results show that the value added tax reporting procedure at PT. Bumi Mitra Buton Abadi in 2014 and 2015 has not complied with the reporting procedure, namely the reported party is empty (0) and the date of reporting was carried out in 2016. However, in 2016 PT. Bumi Mitra Buton Abadi performs reporting procedures correctly. Due to mistakes in 2014 and 2015 PT. Bumi Mitra Buton Abadi received a tax sanction in the form of an examination. Sanctions obtained by PT. Bumi Mitra Buton Abadi can be forgiven by utilizing the tax amnesty program in the first phase held by the government.

\section{Keywords: Tax, Tax Reporting, Value Added Tax}

\section{PENDAHULUAN}

Dalam menjalankan roda pemerintahan dan pembangunan di Indonesia, pemerintah sangat membutuhkan dana yang tidak sedikit. Dana tersebut dikumpulkan dari segenap potensi sumber daya yang dimiliki oleh negara, baik berupa hasil kekayaan alam maupun iuran dari masyarakat. Salah satu bentuk iuran dari rakyat kepada negara adalah pembayaran pajak..Kontribusi pembayaran pajak terhadap penerimaan negara diharapkan semakin meningkat dari tahun ke tahun, seiring dengan semakin menurunnya 
cadangan minyak dan gas bumi yang dimiliki serta berfluktuasinya harga jual minyak dan gas bumi di pasar dunia.

Pembayaran pajak kepada negara dilakukan oleh wajib pajak.Wajib pajak adalah orang pribadi atau badan meliputi pembayar pajak, pemotong pajak, dan pemungut pajak yang mempunyai hak dan kewajiban perpajakan sesuai dengan ketentuan perundangundangan [1].

Untuk dapat memaksimalkan kontribusi penerimaan pajak, sejak tahun 1984 sistem pemungutan pajak di Indonesia menggunakan sistem self assessment.Sistem self assessment adalah sistem pemungutan pajak yang memberi wewenang penuh kepada wajib pajak untuk menghitung, memperhitungkan, menyetorkan, dan melaporkan sendiri besarnya utang pajak [2].Pengetahuan yang memadai dalam penerapan self assessment system di Indonesia adalah salah satu syarat yang harus dimiliki wajib pajak agar bisa memenuhi kewajiban perpajakannya dengan baik dan benar. Oleh karena itu, wajib pajak harus mengetahui apa saja yang merupakan hak dan kewajiban wajib pajak dalammelaksanakan kewajiban perpajakannya sehingga dapat diketahui apakah kewajiban perpajakan telah dijalankan dengan benar oleh wajib pajak.

Salah satu jenis pajak yang disetor wajib pajak kepada negara adalah Pajak Pertambahan Nilai (PPN).PPN adalah pajak atas konsumsi barang dan jasa di daerah pabean yang dikenakan secara bertingkat disetiap jalur produksi dan distribusi.Subjek PPN adalah Pengusaha Kena Pajak(PKP). PKP adalah Pengusaha yang melakukan penyerahan Barang Kena Pajak (BKP) dan atau penyerahan Jasa Kena Pajak (JKP) yang dikenakan pajak berdasarkan Undang-undang Pajak Pertambahan Nilai, tidak termasuk pengusaha kecil yang batasannya ditetapkan dengan Peraturan Menteri Keuangan, kecuali Pengusaha Kecil yang memilih untuk dikukuhkan sebagai Pengusaha Kena Pajak [3].

PT. Bumi Mitra Buton Abadi merupakan salah satu wajib pajak badan yang telahdikukuhkan sebagai Pengusaha Kena Pajak (PKP) yang bergerak dibidang produksi aspal.Sebagai PKP, PT Bumi Mitra Abadi wajib untuk memungut pajak terutang, menyetorkan pajak pertambahan nilai yang masih harus dibayar dalam hal pajak keluaran lebih besar dari pajak masukan yang dapat dikreditkan, serta menyetorkan pajak penjualan atas barang mewah yang terutang dan melaporkan perhitungan pajak sesuai dengan peraturan undang-undang PPN.Agar tidak terkena sanksi perpajakan berupa denda atauteguran, PT Bumi Mitra Abadiperlu untuk memperhatikankewajibannya 
tersebut.Oleh sebab itu berdasarkan latar belakang diatas maka pertanyaan penelitian ini adalah (a) bagaimana prosedur pelaporan pajak pertambahan nilai PT. Bumi Mitra Buton Abadi?; (b) Apakahprosedur pelaporan pajak pertambahan nilai PT. Bumi Mitra Buton Abadi telah sesuai dengan UU PPN No.42 Tahun 2009?

\section{METODE PENELITIAN}

Populasi adalah suatu wilayah yang bersifat general yang terdiri dari subjek ataupun objek dengan karateristik tertentu [4].Populasi yang diambil dalam penelitian ini berupa Surat Pemberitahuan Masa PPN.Sampel adalah sebagian dari subyek dalam populasi yang diteliti, yang sudah tentu mampu secara representative dapat mewakili populasinya [5].Untuk itu sampel yang diambil yakni Surat Pemberitahuan Masa PPN dari tahun 2014-2016.

Data yamg digunakan dalam peneelitian ini adalah data kualitatif berupa wawancara dan dokumen profil perusahaan.Selain itu, penelitian ini juga menggunakan data kuantitatif berupa data penjualan dan pembelian yang tertuang dalam SPT Masa PPN Baik dalam lampiran A2 Dan B2.Sumber data yang diteliti yakni data primer dan data sekunder. Data primer adalah data yang di peroleh langsung dari perusahaan atau tempat penelitian [6].Data tersebut berupa wawancara dengan pihak perusahaan.Sedangkan untuk data sekunder berupaSPT Masa PPNdari tahun 20142016.Dalam mengumpulkan data peneliti menggunakan teknik :

1. Wawancara, yakni menanyai langsung kepada bagian tax accounting di PT. Bumi Mitra Buton Abadi.

2. Studi pustaka, yakni mengambil data dari buku-buku terkait Pajak Pertambahan Nilai Dan Aplikasi Tax Base (Aplikasi Terpercaya yang banyak di gunakan oleh perusahaan dan kantor pelayanan pajak untuk mendapatkan update peraturan dan berita pajak terkini)

3. Dokumentasi, yakni mengumpulkan dokumen-dokumen yang berkaitan dengan pajak pertambahan nilai pada PT. Bumi Mitra Buton Abadi.

Metode analisis data yang digunakan dalam penelitian ini yaitu dengan mengunakan metode analisis deskriptif kualitatif yang merupakan suatu metode yang digunakan untuk menggambarkan atau menganalisis suatu hasil penelitian tetapi tidak digunakan untuk membuat kesimpulan yang lebih luas [4].

Penelitian ini dilakukan dengan cara menganalisis pelaporan pajak pertambahan nilai pada PT. Bumi Mitra Buton Abadi yang didasari pada undang-undang pajak 
pertambahan nilai nomor 42 tahun 2009, yang meliputi objek pajak, subjek pajak, tarif pajak, dasar pengenaan pajak, cara perhitungan PPN, saat terutangnya PPN, mekanisme pengkreditan, dan pemungut PPN yang nantinya akan dilaporkan dalam bentuk pelaporan masa pajak dengan mengunakan alat analisis deskriptif yang menggambarkan suatu keadaan perusahaan yang sebenarnya untuk ditarik suatu kesimpulan.

\section{HASIL DANPEMBAHASAN}

\section{a. Hasil Penelitian}

Dari hasil analisis data Surat Pemberitahuan Masa PPN dan laporan raba rugiPT Bumi Mitra Buton Abadi selama tahun 2014 hingga tahun 2016 diketahui bahwa omset yang diperoleh PT Bumi Mitra Buton Abadi pada tahun 2014 mencapai 11.8 Milyar, dan pembelian sebanyak 3 Milyar.Sedangkan pada tahun 2015 omsetnya mencapai 29 Milyar, dan pembelian sebanyak 13 milyar.Untuk tahun 2016 omset PT. Bumi Mitra Buton Abadi mencapai 27 Milyar, dan pembelian sebanyak 8 Milyar.

Namun, tingginya omset yang diperoleh PT. Bumi Mitra Buton Abadi tidak diimbangi dengan pelaporan PPN yang sesuai dengan ketentuan perpajakan. Hal ini dapat dilihat pada saat pelaporan PPN selama tahun 2014 dan 2015,PT. Bumi Mitra Buton Abadi melaporkan pajak pertambahan nilainyanihil (kosong) serta dilaporkan pada tahun 2016.

Berdasarkan hasil wawancara dengan narasumber dari pihak PTBumi Mitra Buton Abadi, diketahui bahwa ketidaksesuaian pelaporan SPT Masa PPN disebabkan oleh kurangnya pemahaman terkait prosedur pelaporan pajak pertambahan nilai mulai dari subjek pajak pertambahan nilai, objek pajak pertambahan nilai, tarif pajak pertambahan nilai, dasar pengenaan pajak pertambahan nilai, cara perhitungan pajak pertambahan nilai, saat terutangnya pajak pertambahan nilai, mekanisme pengkreditan pajak pertambahan nilai, dan pemungut pajak pertambahan nilai (saat pemungutan pajak pertambahan nilai, cara pemungutan pajak pertambahan nilai serta saat penyetoran pajak pertambahan nilai) oleh PTBumi Mitra Buton Abadi sebagai wajib pajak.

Kondisi tersebut berbeda pada tahun 2016. Di tahun 2016 PT. Bumi Mitra Buton Abadi telah melaporkan SPT Masa PPN miliknya secara benar sesuai dengan ketentuan UU PPN Nomor 42 Tahun 2009 walaupun pada bulan januari dan februari 2016PT. Bumi Mitra Buton Abadi masih belum sesuai prosedur pelaporan pajak pertambahan nilai yakni terlapor nihil (0) dan waktu pelaporan melewati bulan yang ditentukan. 


\section{b. Pembahasan}

\section{Subjek Pajak Pertambahan Nilai}

Subjek pajak pertambahan nilai ialah Pengusaha Kena Pajak (PKP).Syarat pengukuhan pengusaha kena pajak berdasarkan Peraturan Menteri Keuangan No.197/PMK.03/2013 Pasal 4) yakni Pengusaha kecil yang omsetnya telah melampaui batasan peredaran bruto (omzet) Rp 4,8 miliar sampai dengan suatu bulan dalam satu tahun buku, wajib melaporkan usahanya untuk dikukuhkan menjadi Pengusaha Kena Pajak paling lama akhir bulan berikutnya setelah bulan saat jumlah peredaran bruto dan/atau penerimaan brutonya melebihi Rp 4.800.000.000,00 (empat miliar delapan ratus juta rupiah) [7], peraturan ini sesuai dengan kondisi yang dimiliki oleh PT Bumi Mitra Buton Abadi yang penghasilan bruto sebulannya melebihi Rp. 4.800.000.000. Hal ini dapat di lihat padatabel rincian pendapatan dan pembelian PT. Bumi Mitra Buton Abadi dari tahun 2014 hingga 2016.

\section{Objek Pajak Pertambahan Nilai}

Objek pajak pertambahan nilai yakni Barang Kena Pajak Dan Jasa Kena Pajak.Di PT. Bumi Mitra Buton Abadi terdapat objek pajak berupa barang kena pajak yakni Ready Mix Aspal Curah (RMA Curah), Dan Ready Mix Aspal Karung (RMA Karung). Inilah Barang Kena Pajak (BKP) yang wajib dihitung, dipungut, dan dilaporkan PPN-nya oleh PT.Bumi Mitra Buton Abadi, namun tidak dilakukan pada tahun 2014 dan 2015.PPN BKP tersebut baru dihitung, dipungut, dan dilaporkan pada tahun 2016.

\section{Tarif Pajak Pertambahan Nilai}

Tarif PPN umumnya adalah $10 \%$, tetapi dengan peraturan pemerintah dapat diubah serendah-rendahnya 5\% dan setinggi-tingginya 15\%.[8]. PT. Bumi Mitra Buton Abadi dalam menentukan tarif pajak di tahun 2016 mengikuti tarif umum pajak pertambahan nilai yaitu $10 \%$ yang diketahui dari Kantor Pelayanan Pajak Pratama Kota Baubau. Untuk itu dari segi perhitungan tarif pajak PPN, PT Bumi Mitra Buton Abadi telah sesuai dengan ketentuan undang-undang perpajakan.

\section{Dasar Pengenaan Pajak Pertambahan Nilai}

Dasar pengenaan pajak diatur dalam UU Nomor 42 tahun 2009 Pasal 1 jo. PP Nomor 1 tahun 2012, adalah jumlah harga jual, penggantian, nilai impor, nilai ekspor, atau nilai lain yang ditetapkan dengan Keputusan Menteri Keuangan yang dipakai sebagai dasar 
untuk menghitung Pajak Pertambahan Nilai atau Pajak Pertambahan Nilai dan Pajak Penjualan atas Barang Mewah yang terutang.

Dalam kaitannya dengan Dasar Pengenaan Pajak (DPP) pertambahan nilai PT. Bumi Mitra Buton Abadi adalah harga jual objek pajak pertambahan nilai.Artinya dasar pengenaan pajak untuk barang yang dijual yakni RMA Curah 1.050.000 dan RMA Karung 1.200.000, inilah yang nantinya dikalikan dengan tarif pajak pertambahan nilai.

\section{Cara Perhitungan Pajak Pertambahan Nilai}

Tatacara perhitungan PPN di atur dalam UU Nomor 42 tahun 2009 Pasal 8A, Pajak Pertambahan Nilai yang terutang dihitung dengan cara mengalikan tarif dengan Dasar Pengenaan Pajak.

PPN = Tarif Pajak x Dasar Pengenaan Pajak

Perhitunganpajak pertambahan nilai PT. Bumi Mitra Buton Abadi di tahun 2016 adalah $10 \%$ x harga jual atau (10\% x Rp. 1.050.000) untuk produk RMA curah dan (10\% x Rp. 1.200.000) untuk RMA Karung. Hasil perkalian persentase tarif pajak dan harga jual itulah yang kemudian wajib dipotong dan dipungut oleh PT. Bumi Mitra Buton Abadiuntuk disetorkan ke kas negara. Besaran pajak PPN yang wajib dipotong, dipungut dan disetorkan oleh PT. Bumi Mitra Buton Abadidari penjualan produknyaadalah sebesar Rp. 105.000 untuk RMA Curah dan Rp. 120.000 Untuk RMA Karung.

\section{Saat Terutangnya Pajak Pertambahan Nilai}

Berdasarkan UU Nomor 42 Tahun 2009 Pasal 11 ayat 1 Saat terutangnya pajak pertambahan nilai yakni saat penyerahan barang atau jasa kena pajak. Dalam hal ini dimaksudkan pajak pertambahan nilai terhutang di PT. Bumi Mitra Buton Abadi adalah saat penyerahan barang kepada pelanggan bukan pada saat dikeluarkan order penjualan.

\section{Mekanisme Pengkreditan Pajak Pertambahan Nilai}

Berdasarkan UU Nomor 4 tahun 2009 Pasal 9 ayat 2Pengkreditan Pajak Masukan dan Pajak Keluaran adalah Pajak keluaran - Pajak Masukan.

Pengkreditan tersebut apabila menghasilkan positif (+) maka PT. Bumi Mitra Buton Abadi diwajibkan menyetor uang sejumlah tersebut, dan apabila hasil pengkreditan minus (-) maka PT. Bumi Mitra Buton Abadi berhak mengambil kelebihan pembayaran tersebut dengan cara mengkreditkan kemasa pajak berikutnya. 


\section{Pemungut Pajak Pertambahan Nilai (Saat Pemungutan, Cara Pemungutan, Saat Penyetoran, Dan Saat Penyampaian SPT).}

Pemungut pajak pertambahan nilai salah satunya adalah Badan Usaha Tertentu, Badan Usaha Tertentu di sini di maksudkan adalah PT. Bumi Mitra Buton Abadi Karena telah di kukuhkan sebagai pengusaha kena pajak.

Saat Pemungutan Pajak Pertambahan Nilai adalah saat penyerahan barang, cara pemungutan dengan cara mengalikan tarif dengan dasar pengenaan pajak pertambahan nilai, saat penyetoran dan saat pelaporan yakni akhir bulan berikutnya apabila masa pajak Januari 2017 maka disetor dan dilapor pada akhir bulan Februari.

\section{Sanksi}

Pemungut PPN termasuk dalam pengertian Wajib Pajak dan Penanggung Pajak sesuai Pasal 1 angka 1 dan angka 25 Undang-undang Nomor 6 Tahun 1983 tentang Ketentuan Umum dan Tata Cara Perpajakan sebagaimana telah diubah terakhir dengan Undangundang Nomor 16 Tahun 2000, maka kepadanya dapat diterbitkan Surat Tagihan Pajak dan atau Surat Ketetapan Pajak [9].

Untuk itu sanksi yang disebabkan oleh ketidaktahuan atas prosedur pelaporan pajak pertambahan nilai di tahun 2014 dan 2015 PT Bumi Mitra Buton Abadi telah mendapat teguran berupa teguran pemeriksaan dari Kantor Pelayanan Pajak Pratama Kota Baubau.

Sanksi berupa teguran tersebut dapat terampuni dengan berlakunya program tax amnesty (pengampunan pajak) oleh pemerintah.Tax amnestyialah penghapusan pajak yang seharusnya terutang, tidak dikenai sanksi administrasi perpajakan dan sanksi pidana di bidang perpajakan dengan cara mengungkap harga dan membayar uang tebusan [10].Program ini dapat dimanfaatkan dengan baik oleh PT. Bumi Mitra Buton Abadi di tahun 2016 pada akhir tahap pertama program tax amnesty.Surat keputusan pemberhentian pemeriksaan atas kejadian di tahun 2014-2015 dikeluarkan setelah PT. Bumi Mitra Buton Abadi menyelesaikan/melaporkantax amnesty.

\section{KESIMPULAN}

Berdasarkan hasil penelitian dan pembahasan yang telah dikemukakan sebelumnya, maka kesimpulan yang dapat ditarik dari peneliian ini adalah pelaporan pajak pertambahan nilai PT. Bumi Mitra Buton Abadi di tahun 2014 dan 2015 tidak menaati prosedur pajak pertambahan nilai namun untuk tahun 2016 PT. Bumi Mitra Buton Abadi 
sudah sesuai dengan prosedur pelaporan pajak pertambahan nilai yang diatur dalam UU Nomor 42 Tahun 2009.

\section{SARAN}

Berdasarkan hasil penelitian dan kesimpulan, maka saran yang dapat diberikan antara lain: (1) agar PT. Bumi Mitra Buton Abadi mengupdate peraturan-peraturan baru khususnya peraturan pajak pertambahan nilai sehingga dapat terus melaksanakan pelaporan pajak PPN yang sesuai dengan prosedur UU perpajakan; (2) untuk peneliti selanjutnya peneliti menganjurkan untuk meneliti tentang pelaporan dalam SPT Yang di kaitkan dengan data pembelian dan penjualan.

\section{DAFTAR PUSTAKA}

[1] Republik Indonesia. Undang-Undang Nomor 28 Tahun 2007 tentang Ketentuan Umum dan Tata Cara Perpajakan.

[2] Ilyas, W. B. dan R. Burton. 2013. Hukum Pajak: Teori, Analisis, dan Perkembangannya. Jakarta: Salemba Empat.

[3] Republik Indonesia. Undang-Undang Nomor 42 Tahun 2009 Tentang Perubahan Ketiga Atas Undang-Undang Nomor 8 Tahun 1983 Tentang Pajak Pertambahan Nilai Barang dan Jasa dan Pajak Penjualan Atas Barang Mewah.

[4] Sugiyono. 2012. Metode Penelitian Administrasi. Bandung: Alfabeta

[5]Siswanto, V. A. 2012. Strategi dan Langkah-Langkah Penelitian.Yogyakarta: Graha Ilmu

[6] Kuncoro. 2009. Metode Riset Untuk Bisnis Dan Ekonomi. Jakarta: Erlangga..

[7]Republik Indonesia. Peraturan Menteri Keuangan No. 197/PMK.03/2013 tentang Batasan Pengusaha Kecil Pajak Pertambahan Nilai.

[8]Agoes, Sukrisno. 2010. Akuntansi Perpajakam.Jakarta: Salemba Empat.

[9]Wahyono,Sugeng. 2012. Mengurus Pajak Itu Mudah. Jakarta: PT. Elex Media Komputindo.

[10] Republik Indonesia. Undang-Undang No.11 Tahun 2016 tentang Pengampunan Pajak. 